\title{
Gilvocarcin HE: a new polyketide glycoside from Streptomyces sp
}

\author{
Jiabo Hou ${ }^{1,3}$, Peipei Liu ${ }^{1,3}$, Haijun $\mathrm{Qu}^{2}$, Peng Fu${ }^{1}$, Yi Wang ${ }^{1}$, Zhiying Wang ${ }^{1}$, Ye $\mathrm{Li}^{1}$, Xiancun Teng ${ }^{1}$ and \\ Weiming $\mathrm{Zhu}^{1}$
}

A new antimicrobial polyketide glycoside (1) and three known compounds, gilvocarcins $H(2), V(3)$ and $M(4)$ were isolated from the ethyl acetate extract of Streptomyces sp. QD01-2. The structure of (1) was established by spectroscopic analysis, $X$-ray single crystal diffraction and CD spectra. The new compound (1) showed potent antimicrobial activities against Staphylococcus aureus, Bacillus subtilis, Escherichia coli and Candida albicans, with MIC values of 0.5-5.0 $\mu$ m. Compound (1) also showed weak cytotoxicity against the MCF-7, K562 and P388 cell lines, with IC ${ }_{50}$ values of 36,39 and $45 \mu \mathrm{M}$, respectively. The results showed that the vinyl side chain helps to increase the cytotoxicity and antimicrobial activities of gilvocarcin-type glycosides. In addition, the NMR data of gilvocarcin H (2) were also reported for the first time. The Journal of Antibiotics (2012) 65, 523-526; doi:10.1038/ja.2012.61; published online 1 August 2012

Keywords: antimicrobial activity; cytotoxicity; gilvocarcin HE; polyketide glycoside; Streptomyces

\section{INTRODUCTION}

Producing 13000 bioactive metabolites described, cultured bacteria have been a prolific resource for drug discovery. ${ }^{1}$ About $70 \%$ of these bioactive compounds have been isolated from cultured actinomycetes. $^{2}$ Among them, polyketide metabolites represent a major source for novel chemotherapeutics. ${ }^{3}$ A particularly promising lead structure is gilvocarcin $\mathrm{V}(3)$, the prototype of a family of benzo $[d]$ naphtha[ $[1,2-b]$ pyran-6-one glycosides from Streptomyces spp. ${ }^{4-8}$ Members of this family generally exhibit high antimicrobial and antitumor activities. ${ }^{9}$ Structurally these gilvocarcintype polyketide glycosides differ in the nature of the sugar moiety and the side chain at C-8. ${ }^{10-14}$ As part of our ongoing search for bioactive secondary metabolites from actinomycetes, ${ }^{15-17}$ strain Streptomyces sp. QD01-2 was isolated from the 3-m-deep soil collected at Huiquan Square near Qingdao First Beach, China. Its secondary metabolites showed antibacterial activity against Staphylococcus aureus at a concentration of $100 \mu \mathrm{g} \mathrm{ml}^{-1}$. And a series of peaks with the similar UV absorptions to those of gilvocarcin-type polyketide glycosides ${ }^{4-8}$ were observed at $\lambda_{\max } 242,274,314$ and $386 \mathrm{~nm}$ in the HPLC-UV profile (Supplementary Figure S7). Chemical investigation resulted in the isolation of a new gilvocarcin, gilvocarcin $\mathrm{HE} \mathrm{(1),} \mathrm{along} \mathrm{with}$ the known gilvocarcins $\mathrm{H}(2),{ }^{18} \mathrm{~V}(3),{ }^{5}$ and $\mathrm{M}(4)$ (Figure 1). ${ }^{5} \mathrm{New}$ compound (1) displayed significant antimicrobial activities against $S$. aureus, Escherichia coli, Bacillus subtilis and Candida albicans, with MIC values of $0.5,2.8,5.0$ and $3.6 \mu \mathrm{M}$, respectively. It also showed cytotoxicity against the MCF-7, K562 and P388 cell lines, with $\mathrm{IC}_{50}$ values of 36,39 and $45 \mu \mathrm{M}$, respectively.

\section{RESULTS}

Physico-chemical properties

Compound (1): colorless needles $(\mathrm{MeOH}) ;[\alpha]_{\mathrm{D}}^{23}-122$ (c 0.15 , $\mathrm{MeOH}) ;$ HR-ESI-MS $m / z 513.1757 \quad[\mathrm{M}+\mathrm{H}]^{+}$(calculated for $\mathrm{C}_{27} \mathrm{H}_{29} \mathrm{O}_{10}$, 513.1761); UV (MeOH) $\lambda_{\max }(\log \varepsilon) 242$ (2.51), 244 (2.46), 271 (1.80), 274 (1.94), 314 (0.73), 386 (0.71) nm; CD (MeOH) $\lambda_{\max }(\Delta \varepsilon) 220(+0.3), 243(-2.3), 300(+0.3) \mathrm{nm}$; IR $v_{\max }(\mathrm{KBr})$ 3398, 2926, 2856, 1685, 1651, 1619, 1457, 1433, 1371, 1306, 1247, $1166,1083,1053 \mathrm{~cm}^{-1} ;{ }^{1} \mathrm{H}$ and ${ }^{13} \mathrm{C}$ NMR (see Table 1).

Compound (2): yellow amorphous powder; $[\alpha]_{\mathrm{D}}^{23}-208$ (c 0.15 , $\mathrm{MeOH}$ ); ESI-MS $499[\mathrm{M}+\mathrm{H}]{ }^{+} ;{ }^{1} \mathrm{H}$ and ${ }^{13} \mathrm{C}$ NMR (see Table 1, Supplementary Figures S1 and S2).

Compound (3): yellow amorphous powder; $[\alpha]_{\mathrm{D}}^{23}-205$ (c 0.15 , $\mathrm{MeOH}) ; \mathrm{ESI}-\mathrm{MS} 495[\mathrm{M}+\mathrm{H}]^{+} ; \mathrm{CD}(\mathrm{MeOH}) \lambda_{\max }(\Delta \varepsilon) \mathrm{nm} 220$ $(+4.6), 243(-1.5), 303(+0.3) ;{ }^{1} \mathrm{H}$ and ${ }^{13} \mathrm{C}$ NMR (see Table 1, Supplementary Figure S8).

\section{Biological activity}

The antimicrobial activities of these four compounds were evaluated by an agar dilution method. ${ }^{20}$ The results showed that compounds 1-4 displayed antimicrobial activity against S. aureus, B. subtilis, E. coli and C. albicans (Table 2), while compounds 1-4 were inactive against Aerobacter aerogenes and Pseudomonas aeruginosa (MIC $>100 \mu \mathrm{M})$. Compounds (1) and (3) are more active than compounds (2) and (4), and (2) is more active than (4), indicating that both unsaturation and oxidation at the side chain result in an increase of antimicrobial activities of gilvocarcin-type glycosides.

\footnotetext{
${ }^{1}$ Key Laboratory of Marine Drugs, Ministry of Education of China, Ocean University of China, Qingdao, PR China and ${ }^{2}$ Department of Pharmacy, Affiliated Hospital of Medical College, Qingdao University, Qingdao, PR China

${ }^{3}$ These authors equally contributed to this work.

Correspondence: Dr W Zhu, Key Laboratory of Marine Drugs, Ministry of Education of China, Ocean University of China, Qingdao 266003, PR China.

E-mail: weimingzhu@ouc.edu.cn
}

Received 17 February 2012; revised 25 June 2012; accepted 29 June 2012; published online 1 August 2012 
Table $1{ }^{1} \mathrm{H}$ - NMR and ${ }^{13} \mathrm{C}$-NMR data for $1-3\left(600,150 \mathrm{MHz}\right.$, DMSO- $d_{6}$, TMS, $\delta$ p.p.m.)

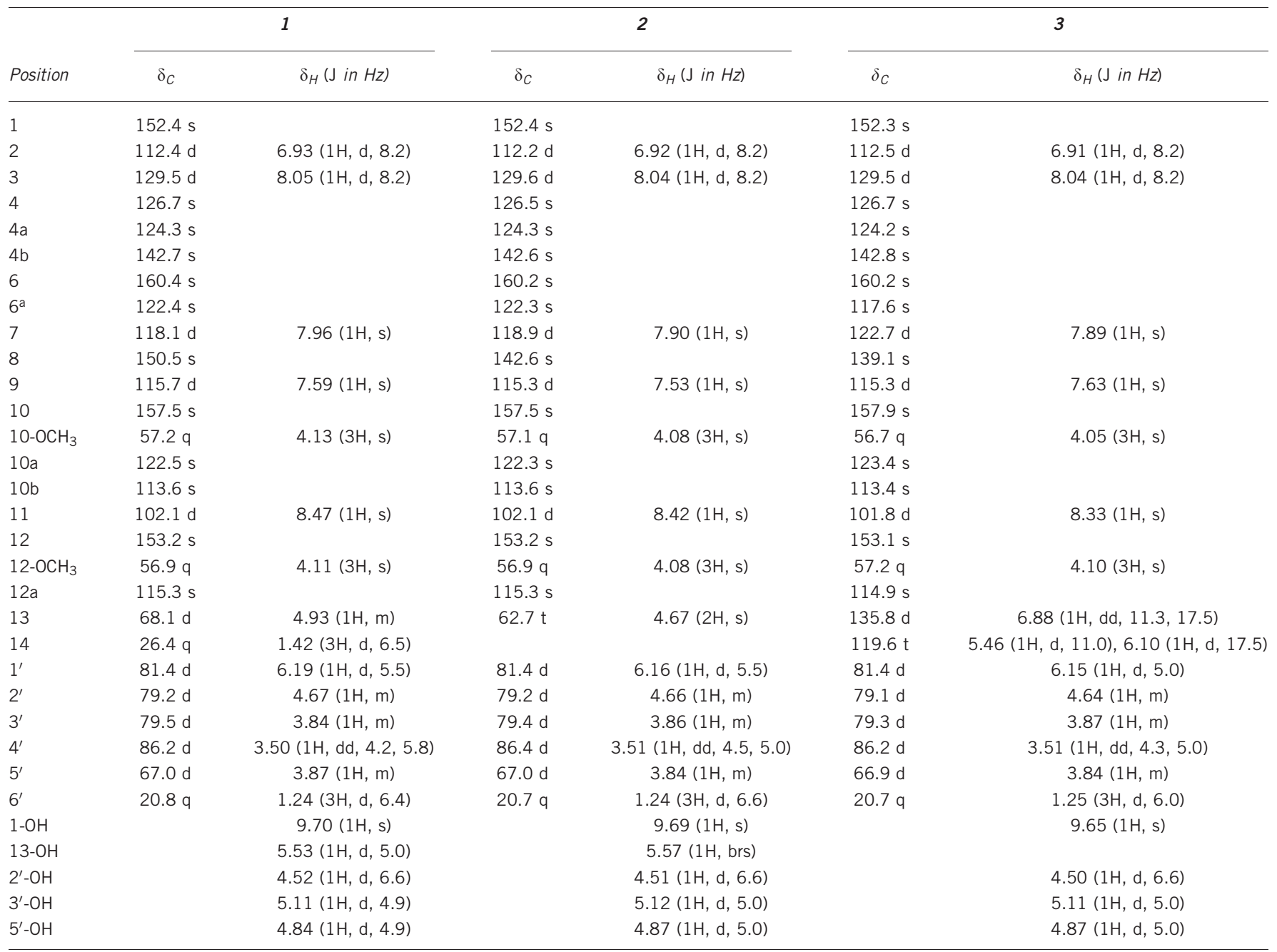

Abbreviations: brs, broad singlet; d, doublet; dd, doublet of doublets; m, multiplet, s, singlet.

Table 2 The MIC values of compounds $1-4$ against pathogens ( $\mu \mathrm{m})$

\begin{tabular}{lcclc}
\hline Compound & $\mathbf{1}$ & $\mathbf{2}$ & $\mathbf{3}$ & $\mathbf{4}$ \\
\hline Staphylococcus aureus & 0.5 & 0.5 & 0.1 & 1.5 \\
Escherichia coli & 2.8 & 5 & 3 & 5 \\
Bacillus subtilis & 5.0 & 20 & 1.5 & $>50$ \\
Candida albicans & 3.6 & 25 & 4 & 25 \\
\hline
\end{tabular}

The cytotoxicities of compounds $\mathbf{1}-\mathbf{4}$ were also evaluated against MCF-7, K562 and P388 cell lines by the MTT method. ${ }^{21}$ The results showed that compound (3) was the most active against the tested tumor cell lines, indicating that the vinyl side chain might have an important role in cytotoxicity of gilvocarcin-type glycosides (Table 3).

\section{Structure determination}

Compound (1) was obtained as colorless needles with the molecular formula of $\mathrm{C}_{27} \mathrm{H}_{28} \mathrm{O}_{10}$ from the HR-ESI-MS peak at $\mathrm{m} / \mathrm{z}$ $513.1757[\mathrm{M}+\mathrm{H}]^{+}$. Its UV spectrum showed characteristic peaks of gilvocarcin-type polyketide chromophore at $\lambda_{\max } 242,274,314$ and $386 \mathrm{~nm}^{4-8}$ The IR spectrum indicated that (1) possesses hydroxyl
Table 3 The $\mathrm{IC}_{50}$ values of compounds $1-4$ against three tumor cell lines ( $\mu \mathrm{m})$

\begin{tabular}{lcccc}
\hline Compound & $\mathbf{1}$ & $\mathbf{2}$ & $\mathbf{3}$ & $\mathbf{4}$ \\
\hline MCF-7 & 36 & 38 & 1.8 & 17 \\
K562 & 39 & 31 & 0.8 & 15 \\
P388 & 45 & 35 & 1.1 & 21 \\
\hline
\end{tabular}

$\left(3398 \mathrm{~cm}^{-1}\right)$, carbonyl $\left(1685 \mathrm{~cm}^{-1}\right)$, aromatic system (1619, $\left.1589 \mathrm{~cm}^{-1}\right)$ and ether groups $\left(1166 \mathrm{~cm}^{-1}\right)$. The ${ }^{1} \mathrm{H}$ NMR spectrum showed 28 proton signals including five aromatic protons at $\delta_{\mathrm{H}}$ $8.47 \sim 6.93$, two methoxy protons, two methyl protons and five oxygenated methine protons at $\delta_{\mathrm{H}} 6.19 \sim 3.50$ (Table 1, Supplementary Figure S1). The ${ }^{13} \mathrm{C}$ NMR spectrum displayed 27 carbon signals (Supplementary Figure S2) that were classified by DEPT (Supplementary Figure S3) and HMQC (Supplementary Figure S4) spectra as two methoxy carbons, two methyl carbons, five olefinic methine carbons, six oxygenated methine carbons, 11 olefinic quaternary carbons (four oxygenated) and one conjugated ester carbonyl carbon. These NMR data were very similar to those of gilvocarcin $\mathrm{V},{ }^{5}$ further indicating the nature of gilvocarcin-type 
polyketide glycoside of (1). Compared with those of gilvocarcin V, the NMR differences of (1) embodied in the replacement of $-\mathrm{CH}=\mathrm{CH}_{2}$ signals by $-\mathrm{CH}(\mathrm{OH}) \mathrm{CH}_{3}$ signals that was further supported by ${ }^{1} \mathrm{H}-{ }^{1} \mathrm{H}$ COSY correlations between $\mathrm{H}_{3}-14\left(\delta_{\mathrm{H}} 1.42\right)$ with $\mathrm{H}-13$ $\left(\delta_{\mathrm{H}} 4.93\right)$ and $\mathrm{H}-13$ with HO-13 $\left(\delta_{\mathrm{H}} 5.53\right)$ (Supplementary Figure S5). Furthermore, obvious downfield shifts for C-8, C-6a and H-7 and upfield shifts for C-7 and H-9 were observed between (1) and gilvocarcin V. These observations suggested that compound (1) is the hydrated derivative of gilvocarcin $\mathrm{V}$ at the $\mathrm{C}-8$ side chain, which was further supported by the key HMBC correlations from $\mathrm{H}-7\left(\delta_{\mathrm{H}} 7.96\right)$ to $\mathrm{C}-6\left(\delta_{\mathrm{C}} 160.4\right), \mathrm{C}-6 \mathrm{a}\left(\delta_{\mathrm{C}} 122.4\right), \mathrm{C}-9\left(\delta_{\mathrm{C}} 115.7\right)$ and $\mathrm{C}-13\left(\delta_{\mathrm{C}}\right.$ $168.1)$, from $\mathrm{H}-9\left(\delta_{\mathrm{H}} 7.59\right)$ to C-8 $\left(\delta_{\mathrm{C}} 150.5\right), \mathrm{C}-10\left(\delta_{\mathrm{C}} 157.5\right), \mathrm{C}-10 \mathrm{a}$ $\left(\delta_{\mathrm{C}} 122.5\right)$ and $\mathrm{C}-13$, and from $\mathrm{H}_{3}-14$ to $\mathrm{C}-8$ (Figure 2, Supplementary Figure S6). Single crystal X-ray diffraction analysis further confirmed the structure (Figure 3), and its relative configuration was also resolved. As the absolute configuration of gilvocarcin $\mathrm{V}$ had been resolved by total synthesis, ${ }^{19}$ the absolute configuration of fucose moiety of compound (1) could be deduced from the

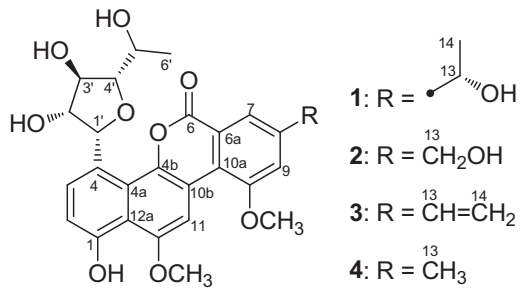

Figure 1 The structures of compounds 1-4.

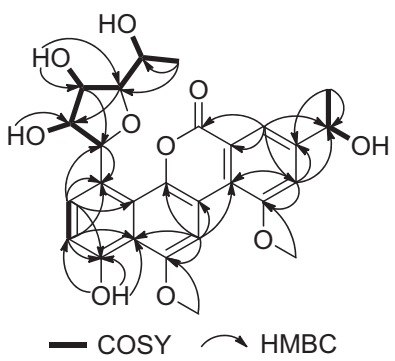

Figure $2{ }^{1} \mathrm{H}-{ }^{1} \mathrm{H}$ COSY and HMBC correlations of (1). comparison of CD spectra between (1) and gilvocarcin V (3). Thus, the CD curves of (1) and gilvocarcin V (3) were measured in $\mathrm{MeOH}$. Compound (1) exhibited CD cotton effects at $220 \mathrm{~nm}(\Delta \varepsilon+0.29)$, $243 \mathrm{~nm}(\Delta \varepsilon-2.3)$ and $300 \mathrm{~nm}(\Delta \varepsilon+0.29)$, similar to those of $(3)$ at $219 \mathrm{~nm}(\Delta \varepsilon+4.6), 254 \mathrm{~nm}(\Delta \varepsilon-1.5)$ and $303 \mathrm{~nm}(\Delta \varepsilon+0.25)$ (Figure 4), indicating $\mathrm{D}$-fucose (that is, $1^{\prime} R, 2^{\prime} R, 3^{\prime} R, 4^{\prime} S, 5^{\prime} R$ ). According to the X-ray crystal structure, the absolute configuration of C-13 was therefore determined as $S$-. Consequently, the structure of gilvocarcin HE (1) was elucidated to be 4 - $[(2 R, 3 R, 4 R, 5 S)-3,4-$ dihydroxy-5-(1S-hydroxyethyl) tetrahydrofuran-2-yl]-1-hydroxy-8-(1Shydroxyethyl)-10,12-dimethoxy-6H-dibenzo[c,h]chromen-6-one.

\section{METHODS}

\section{General experimental procedures}

Optical rotations were obtained on a JASCO P-1020 digital polarimeter (JASCO Corporation, Tokyo, Japan). IR spectra were recorded using a Bruker model. UV spectra were recorded on Beckman DU 640 spectrophotometer (Beckman, Brea, CA, USA). ${ }^{1} \mathrm{H},{ }^{13} \mathrm{C}$ NMR and DEPT spectra and 2D-NMR were recorded on a JEOL JNM-ECP 600 spectrometer (JEOL Ltd., Tokyo, Japan) using TMS as internal standard, and chemical shifts were recorded as $\delta$ values. ESI-MS was measured on a Q-TOF Ultima Global GAA076 LC mass spectrometer (Waters, Milford, MA, USA). Semi-preparative HPLC was performed using an ODS column (YMC-pack ODS-A, $10 \times 250 \mathrm{~mm}^{2}, 5 \mu \mathrm{m}, 4 \mathrm{ml} \mathrm{min}^{-1}$ ).

\section{Strain}

The Streptomyces sp. QD01-2 was isolated from a 3-m-deep soil sample collected at Huiquan Square near Qingdao First Beach, Shandong province of China. It was identified according to its morphological characteristics and

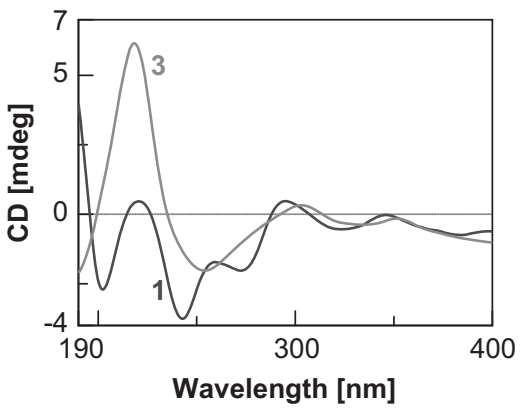

Figure 4 The CD curve of (1) (blue) and (3) (red). A full color version of this figure is available at The Journal of Antibiotics journal online.

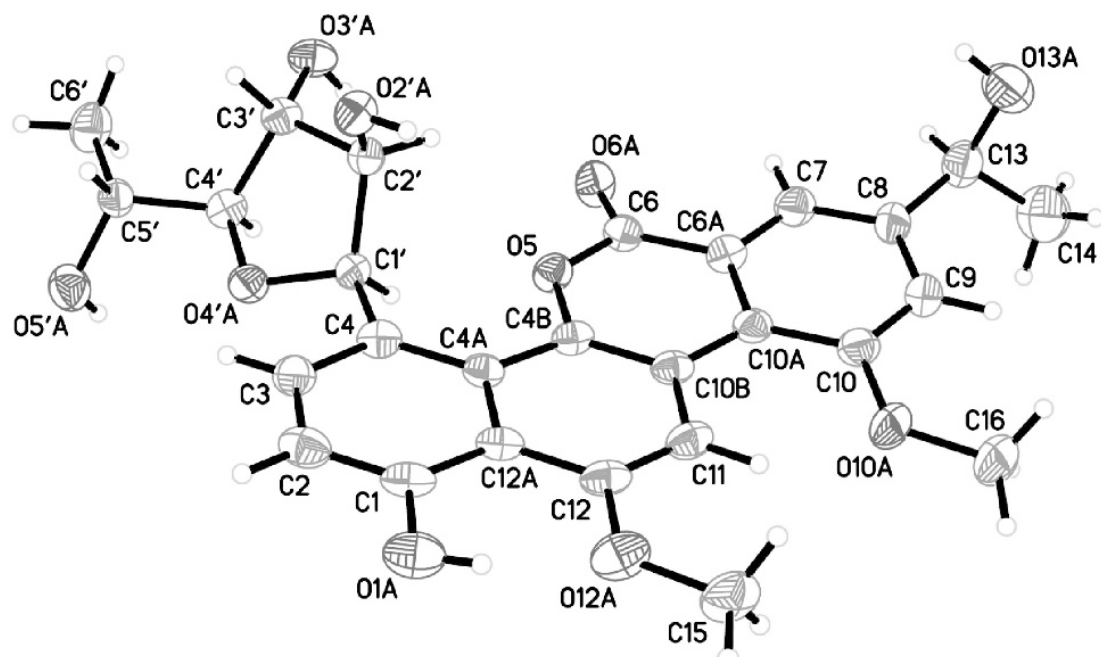

Figure 3 Final X-ray drawing of (1). A full color version of this figure is available at The Journal of Antibiotics journal online. 
$16 \mathrm{~S}$ rRNA sequences. The voucher specimen is deposited in our laboratory at $-80{ }^{\circ} \mathrm{C}$. The working strain was prepared on a Gause's Synthetic Agar medium and stored at $4{ }^{\circ} \mathrm{C}$.

\section{Fermentation}

The Streptomyces sp. QD01-2 was incubated on a rotary shaker (180 r.p.m.) at $28^{\circ} \mathrm{C}$ for 8 days in $500 \mathrm{ml} \times 200$ conical flasks each containing $150 \mathrm{ml}$ of a liquid medium composed of glucose $(3 \mathrm{~g})$, beef extract $(0.45 \mathrm{~g})$, amidulin $(1.5 \mathrm{~g})$, yeast extract $(1.5 \mathrm{~g})$, corn steep liquor $(0.15 \mathrm{~g}), \mathrm{NaCl}(0.075 \mathrm{~g}), \mathrm{MgSO}_{4}$ $(0.075 \mathrm{~g}), \mathrm{KH}_{2} \mathrm{PO}_{4}(0.075 \mathrm{~g}), \mathrm{CaCO}_{3}(0.3 \mathrm{~g})$, adjusting its $\mathrm{pH}$ to 7.0 .

\section{Extraction and isolation}

The fermented whole broth $(80 \mathrm{l})$ was extracted three times with an equal volume of EtOAc to give an ethyl acetate solution. The ethyl acetate solution was concentrated in vacuo to give a crude extract $(32 \mathrm{~g})$. The crude extract was then subjected to vacuum liquid chromatography using step gradient elution with $\mathrm{CH}_{2} \mathrm{Cl}_{2}-\mathrm{MeOH}(100: 0,100: 1,50: 1,30: 1,20: 1,10: 1)$ to give six fractions (fractions 1-6) based on TLC properties. Fraction 4 (2g) was washed with $\mathrm{MeOH}$ to give insoluble yellow amorphous powder. The yellow amorphous powder was further separated by semi-preparative HPLC (68\% $\mathrm{MeOH}-\mathrm{H}_{2} \mathrm{O}$ ) to yield (1) (4 mg, $\left.t_{\mathrm{R}} 10.2 \mathrm{~min}\right)$ and $(2)\left(2 \mathrm{mg}, t_{\mathrm{R}} 6.4 \mathrm{~min}\right)$ Fraction five (5g) was washed with $\mathrm{MeOH}$ to give insoluble yellow amorphous powder that was further separated by semi-preparative HPLC $\left(60 \% \mathrm{CH}_{3} \mathrm{CN}-\right.$ $\left.\mathrm{H}_{2} \mathrm{O}\right)$ to yield (3) (10 mg, $\left.t_{\mathrm{R}} 11.5 \mathrm{~min}\right)$ and $(4)\left(18 \mathrm{mg}, t_{\mathrm{R}} 9.1 \mathrm{~min}\right)$.

\section{$\mathrm{X}$-ray structure determination of (1)}

Compound (1) was obtained as a colorless monoclinic crystal with molecular formula $\mathrm{C}_{27} \mathrm{H}_{32} \mathrm{O}_{12}$. Space group $P 2(1) / c, a=16.9509(17) \AA, b=4.8840(4) \AA$, $c=31.013(3) \AA, \alpha=90.00^{\circ}, \beta=90.00^{\circ}, \gamma=90.00^{\circ}, V=2567.5(4) \AA^{3}, Z=4$, $D_{\text {calcd }}=1.419 \mathrm{mg} \mathrm{m}^{-1}, \mu=0.112 \mathrm{~mm}^{-1}, F(000)=1160$, crystal size $0.45 \times$ $0.15 \times 0.12 \mathrm{~mm}^{3}, T=298(2) \mathrm{K}$. A total of 2661 unique reflections $\left(2 \theta<50^{\circ}\right)$ were collected on a CCD area detector diffractometer with graphite monochromated MoKa radiation $(\lambda=0.71073 \AA)$. The structure was solved by direct methods (SHELXS-97) and expanded using Fourier techniques (SHELXL-97). The final cycle of full-matrix least squares refinement was based on 2661 unique reflections $\left(2 \theta<50^{\circ}\right)$ and 356 variable parameters and converged with unweighted and weighted agreement factors of $R_{1}=0.1077$, $R_{\mathrm{W}}=0.1515$ and $R=0.0611$ for $I>2 \operatorname{sigma}(I)$ data. Crystallographic data (excluding structure factors) for structure (1) have been deposited with the Cambridge Crystallographic Data Center as supplementary publication number CCDC 860606. Copies of the data can be obtained, free of charge, on application to CCDC, 12 Union Road, Cambridge CB2 1EZ, UK (fax: + 44 (0)-1223-336033 or e-mail: deposit@ccdc.cam.ac.uk).

\section{Antimicrobial assay}

The antimicrobial activities against E. coli, B. subtilis, A. aerogenes, P. aeruginosa, S. aureus and C. albicans were evaluated by an agar dilution method. ${ }^{20}$ The tested strains were cultivated on LB agar plates for bacteria and on YPD agar plates for C. albicans at $37^{\circ} \mathrm{C}$. The four compounds and positive controls were dissolved in $\mathrm{MeOH}$ at different concentrations from 50 to $0.05 \mu \mathrm{g} \mathrm{ml}^{-1}$ by the continuous 2-fold dilution methods. A $10 \mu \mathrm{l}$ quantity of test solution was absorbed by a paper disk ( $5 \mathrm{~mm}$ diameter) and placed on the assay plates. After $12 \mathrm{~h}$ incubation, zones of inhibition ( $\mathrm{mm}$ in diameter) were recorded. The MICs were defined as the lowest concentration at which no microbial growth could be observed. Ciprofloxacin was used as the positive control for E. coli, B. subtilis, S. aureus, P. aeruginosa and E. aerogenes with MIC values of $0.9,1.2$, $0.3,1.9$ and $3.7 \mu \mathrm{M}$, respectively. Ketoconazole was used as the positive control for C. albicans with MIC values of $0.5 \mu \mathrm{M}$.

\section{Cytotoxicity assay}

The four compounds were evaluated for cytotoxic effects on MCF-7, K562 and P388 cell lines using the MTT method. ${ }^{21}$ In the MTT assay, cell lines were grown in broth RPMI-1640 supplemented with 10\% FBS under a humidified atmosphere of $5 \% \mathrm{CO}_{2}$ and $95 \%$ air at $37^{\circ} \mathrm{C}$. Two hundred microliter of cell suspensions at a concentration of $5 \times 10^{4} \mathrm{cells} \mathrm{ml}^{-1}$ were plated in 96-well microtiter plates and incubated for $24 \mathrm{~h}$. Then, $2 \mu \mathrm{l}$ of the test solutions (in DMSO) were added to each well and further incubated for $72 \mathrm{~h}$. The MTT solution ( $20 \mu \mathrm{l}, 5 \mathrm{mg} \mathrm{ml}^{-1}$ in IPMI-1640 medium) was then added to each well and incubated for $4 \mathrm{~h}$. Old medium containing MTT $(150 \mu \mathrm{l})$ was then gently replaced by DMSO and pipetted to dissolve any formazan crystals formed. Absorbance was then determined on a Spectra Max Plus plate reader (Molecular Devices, Sunnyvale, CA, USA) at $540 \mathrm{~nm}$. The $\mathrm{IC}_{50}$ values were obtained using the Bliss method.

\section{ACKNOWLEDGEMENTS}

This work was supported by grants from the National Natural Science Foundation of China (No. 21172204, 30973680 and 30670219), the National Basic Research Program of China (No. 2010CB833800), from the Major Program for Technique Development Research of New Drugs in China (No. 2009ZX09103-046), and the Special Fund for Marine Scientific Research in the Public Interest of China (No. 2010418022-3). Professor Weijun Li, Yunnan University, identified the actinomycetous strain.

1 Bérdy, J. Bioactive microbial metabolites. J. Antibiot. 58, 1-26 (2005)

2 Kwon, H. C., Kauffman, C. A., Jensen, P. R. \& Fenical, W. Marinisporolides, polyenepolyol macrolides from a marine actinomycete of the new genus Marinispora. J. Org. Chem. 74, 675-684 (2009).

$3 \mathrm{Li}, \mathrm{Y}$. Q. et al. Plasticity in gilocarcin-type C-glycoside pathways: discovery and antitumoral evaluation of polycarcin V from Streptomyces polyformus. Org. Biomol. Chem. 6, 3601-3605 (2008).

4 Nakano, $\mathrm{H}$. et al. Gilvocarcins, new antitumor antibiotics. 1. Taxonomy, fermentation, isolation and biological activities. J. Antibiot. 34, 266-270 (1981).

5 Takahashi, K., Yoshida, M., Tomita, F. \& Shirahata, K. Gilvocarcins, new antitumor antibiotics. 2. Structural elucidation. J. Antibiot. 34, 271-275 (1981).

6 Balitz, D. M. et al. Antitumor agents from Streptomyces anandii: Gilvocarcins V, M and E. J. Antibiot. 34, 1544-1555 (1981).

7 Morimoto, M., Okubo, S., Tomita, F. \& Marumo, H. Gilvocarcins, new antitumor antibiotics. 3. Antitumor activity. J. Antibiot. 34, 701-707 (1981).

8 Tomita, F., Takahashi, K. \& Tamaoki, T. Gilvocarcins, new antitumor antibiotics. 4. Mode of action. J. Antibiot. 35, 1038-1041 (1982).

9 Takahashi, K. \& Tomita, F. Gilvocarcins, new antitumor antibiotics. 5. Biosynthesis of gilvocarcins: incorporation of ${ }^{13} \mathrm{C}$-labeled compounds into gilvocarcin aglycones. J. Antibiot. 36, 1531-1535 (1983).

10 Liu, T. et al. Inactivation of the ketoreductase gilU gene of the gilvocarcin biosynthetic gene cluster yields new analogues with partly improved biological activity. ChemBioChem 10, 278-286 (2009).

11 Yamashita, N., Shin-ya, K., Furihata, K., Hayakawa, Y. \& Seto, H. New ravidomycin analogues, FE35A and FE35B, apoptosis inducers produced by Streptomyces rochei. J. Antibiot. 51, 1105-1108 (1998)

12 Narita, T. et al. Deacetylravidomycin $\mathrm{N}$-oxide, a new antibiotic. Taxonomy and fermentation of the producing organism and isolation, structure and biological properties of the antibiotic. J. Antibiot. 42, 347-356 (1989).

13 Arai, M. et al. Deacetylravidomycin M, a new inhibitor of IL-4 signal transduction, produced by Streptomyces sp.WK-6326. II. Structure Eelucidation. J. Antibiot. 54, 562-566 (2001)

14 Weiss, U., Yoshihira, K., Highet, R. J., White, R. J. \& Wei, T. T. The chemistry of the antibiotics Chrysomycin A and B. Antitumor activity of Chrysomycin A. J. Antibiot. 35, 1194-1201 (1982).

$15 \mathrm{Fu}$, P. et al. Cylic bipyridine glycosides from the marine-derived actinomycete Actinoalloteichus cyanogriseus WH1-2216-6. Org. Lett. 13, 5948-5951 (2011).

$16 \mathrm{Fu}, \mathrm{P}$. et al. $\alpha$-pyronea and diketoiperazine derivatives from the marine-derived actinomycete Nocardiopsis dassonvillei HR10-5. J. Nat. Prod. 74, 2219-2223 (2011).

$17 \mathrm{Fu}, \mathrm{P}$. et al. Cytotoxic bipyridines from the marine-derived actinomycete Actinoalloteichus cyanogriseus WH1-2216-6. J. Nat. Prod. 74, 1751-1756 (2011).

18 Kikuchi, O. et al. Chemical transformation of gilvocarcin $\mathrm{V}$ modification of the sidechain. J. Antibiot. 46, 985-991 (1993)

19 Hosoya, T., Takashiro, E., Matsumoto, T. \& Suzuki, K. Total Synthesis of the gilvocarcins. J. Am. Chem. Soc. 116, 1004-1015 (1994).

20 Zaika, L. L. Spices and herbs: their antimicrobial activity and its determination. J. Food Safety 9, 97-118 (1988).

21 Mosmann, T. Rapid colorimetric assay for cellular growth and survival: application to proliferation and cytotoxicity assays. Immunol. Methods 65, 55-63 (1983). 